\title{
Research on the Influence and Countermeasures of “Abused Entertainment” on Ideological and Political Education in Universities
}

\author{
Zhimei Zhang \\ Wuhan Textile University, Wuhan, 430073, China
}

Keywords: Abused entertainment, Pan-entertainment, Ideological and political education

\begin{abstract}
At present, entertainment has increasingly become a pursuit of modern fashion, but the spread of entertainment has led to the pan entertainment. The ideological and political education in colleges and universities in China is not valued compared to other courses. While the pan entertainment has a great negative impact on the ideological and political education. Therefore, colleges and universities must enrich education content, innovate teaching model and construct a communication platform to cope with the ubiquitous entertainment.
\end{abstract}

\section{Introduction}

Ubiquitous entertainment means that the programs in the media are mostly entertaining, and the overall style is low. Sometimes people even infiltrate some unhealthy entertainment elements into the program in order to delight the audience. This pan entertainment trend is attacking the ideological and political education in Colleges and universities, and it makes the educational objects of college students face many kinds of temptation and influence. Mass media entertainment is the mass media as the carrier, consumerism and hedonism as the core, catering to the public's sensory consumption needs. In the process of production and dissemination, the dissemination of the contents and forms of the incorporation of entertainment elements, eventually making entertainment elements in flood, glibness vulgar phenomenon. Therefore, although it is to play the essential function of entertainment, but it shows an obvious trend of generalization of the entertainment function [1]. With the further development of mass media entertainment, the functions of mass media such as education, inheritance, social watch and so on will give way to entertainment function and even be occupied by entertainment. On the social impact of Pan entertainment, the entertainment function generalization, the weakening of the ideological and political education function of mass media, lost for the correct guidance of public opinion in the community's direction, lost the news events are explained and the necessary moral responsibility. Further speaking, mass media should have a just stand, seriously convey information and provide basic value guidance to the audience, but the tendency of gradual entertainment tends to corrupt the social atmosphere and impact the national psychology. Therefore, we must try to eliminate the negative influence of Pan entertainment on the ideological and political education in colleges and universities, and give full play to its positive influence, and find the appropriate countermeasures to achieve the positive guiding role of Pan entertainment to the ideological and political education in colleges and universities [2].

\section{Influence of Abused Entertainment on Ideological and Political Education in Universities}

\subsection{Damage Teaching Environment}

The current situation is in the flourishing scene of the coexistence of news and entertainment. On the one hand, the mass media is always from the serious news out of the entertainment culture deep. The phenomenon and behavior of Pan entertainment corrupted the social environment unconsciously, and exposed the serious malpractice of its existence. The influence of Pan entertainment on the spiritual and cultural environment in cultural environment is mainly manifested in the impact on 
social psychology and social ideology, making the important guiding role of social and cultural environment on human values and outlook on life weaken. On the one hand, from a social psychological perspective, long-term audience in this entertainment environment under the influence of the employment pressure and the reality of future life stress, always want to through the way of entertainment, to find the fate of the shortcut, in order to escape the cruel reality, looking for a cure for his comfort agent. On the other hand, from the perspective of social consciousness, it is also manifested in the destruction of these factors, such as politics, culture, morality and art. Instead of setting up a serious political nature, news reports have joined the entertainment elements and weakened the ideology and guidance of political culture. Under the background of Pan entertainment, the correct guiding function of mass media has been seriously damaged, and the information it spreads will form a bad social public opinion environment, bringing about the distortion of value evaluation and aesthetics, which is not conducive to the development of Ideological and political education. At the same time, the ubiquitous entertainment also leads to a kind of consumerism, which has a great negative impact on college students, especially the concept of life of college students. Some college students have lost interest in the teaching of Ideological and political theory. Some even resist the ideological and political theory course. They think this course is a waste of time, and the whole idea is too utilitarian and practical. They would be interested in something seemingly entertaining [3].

\subsection{Weaken Ideal Faith}

The extensive vulgar culture of the market and the achievements of its cultural research have formed a fixed alliance from ideology. The alliance generally believes that the vulgar culture plays a very important role. If there is no such vulgar culture, it will not promote the development of the society. So the phenomenon of Pan entertainment not only impacts the daily mainstream consciousness and mainstream culture. If there is an arbitrary spread of the ubiquitous phenomenon and the rapid spread of vulgar culture, it has a direct impact on the consciousness of consumption mainstream [4]. The local culture and political ideas contained in foreign entertainment information cause a certain impact on college students, weaken the influence of Chinese traditional culture on college students, and shake the political beliefs of college students. The students as the main object of Ideological and political education in school, learning pressure and confusion in the future to graduate job, in the fast-paced society background, let the students' psychological burden, especially in increasing social competition, social injustice phenomenon in general situation, students' psychological anxiety and impetuous as can be imagined. In this situation, the entertainment programs emerge as the times require, and undoubtedly adapt to the psychological needs of the people, and make people relax when they laugh. But the reality is that the entertainment of the program has broken through the scale of all kinds of programs and made the program lose its proper taste. In order to please the audience, people have made laugh, gimmick and spoof. The students are very curious and imitating, and they do not have strong ability to distinguish the advantages and disadvantages. In the ideological and behavioral, it is unavoidable to be influenced by the programs they watch. On the other hand, many of the current programs in China are introduced from foreign countries, Japan and South Korea and other foreign countries. If we don't pay attention to controlling foreign ideology in the introduction of program mode, we will have a subtle influence or even distortion on our national values.

\subsection{Hinder Development of Thoughts}

Pan entertainment media content, a large amount of information, can easily lead to the lack of ability to identify the ideological confusion, and the pan entertainment content, lack of depth, students receive the pan entertainment content without creating a deep thinking of the senses can be obtained, so that the university students thought flat, fragmented and superficial, reducing college students' thinking ability, is not conducive to the development of abstract thinking and logical thinking. The type and form of the pan entertainment news content is single, which limits the students' vision, but lacks the attention to the state and the world. Behavior tendencies are people's 
intention to reflect the object of behavior, and it is a state of preparation before taking action. College students spend a lot of time to deal with countless information. They may be addicted to it gradually. They are divorced from the real society and become less sociable with their families and friends, which, to a certain extent, result in personal psychological closure, which will lead to hidden dangers for the future society. A prominent feature of the mass media's ubiquitous entertainment is to promote sensory enjoyment, and the tendency to visualize is an important way to realize the enjoyment of the senses. Social networking, news content and so on, in order to quickly catch the eye, it is used to display a news content which is not suitable for headlines or pictures with a clear heading and a colorful picture, which makes the title lose its original value and slips into entertainment. Television shows a rich visual enjoyment for the audience with more exaggerated expression. The visual image of the entertainment, so that students can easily obtain information without any bother. This makes the college students take on the utilitarian style of reading, which is the most important and light seeking. At the same time, the excessive dependence on the image will lead to the tendency of thinking to be flat.

\section{Strategies of Ideological and Political Education in Universities under the Background of Abused Entertainment}

\subsection{Enrich Education Content}

The traditional ideological and political education pays attention to the ideal and belief. This is the requirement of carrying out the core values of socialism in an all-round way, and it is also an essential element for the educator to form self - cultivation. However, under the new situation of Pan entertainment, we must adhere to the positive direction and make its content rich and comprehensive, with high cultural and technological content. This should be the first to join the common sense of economics, because of the influence of Pan entertainment under the tide of money worship repeatedly, the educated learn economic common sense by understanding and grasp and use the law of economic development, fundamentally do not to undermine social ethos, affect social harmony and bad behavior due to the economic interests of the individual. As the characteristics of the audience's ideological and political character are dynamic and contemporary, the content of education should be constantly changing. The content of philosophy, ethics, politics, educational psychology and so on all make the ideological and political education have the nature that other disciplines cannot replace. We are in an era of new media, the mass media dissemination of information rich, full of sound and color, can meet the different needs of the audience. But at the same time, the widespread entertainment also gradually spread with the development of new media, which has caused a certain impact on the effectiveness of Ideological and political education. Therefore, the knowledge of communication science should be added to the ideological and political education, which is embodied in the ability to train the educated to understand and use the media correctly. The penetration of this content can help educators form a cultural accomplishment under the new media environment of ubiquitous entertainment, which can guide the educated to learn to analyze and measure the value of receiving information, and then form critical thinking ability.

\subsection{Innovate Teaching Model}

We need to improve the ideological and political education teaching mode, correct and standardize the use of education by radio and television, film and drama propaganda tool to further enhance its effectiveness, and the cognitive stage up to the stage of behavior. Therefore, on the one hand, we should prevent the trend of Ideological and political education from becoming more entertaining. On the other hand, we should prevent the ubiquitous entertainment tendency of this educational concept. Due to the universality and permeability of mass media, the educated can consciously accept external information and internalize them into ideas and even actions. So we need to improve the mode of self-education in Ideological and political education. This model of self-education is based on the two-way nature of its educational process, which is the mode of the combination of self - awareness 
and self - control by the educated. We also need to improve the practice of Ideological and political education. We must realize the dual role of Ideological and political education of subject and object, not only in the main body of the request, to make social investigation and visiting, not just the education of passive participation in large-scale public welfare work, work study, and have a complete set of practice operation scheme. We identify practical practical activities, and the formulation of this scheme should follow its principles and avoid false big space. We must use certain educational means to effect the content of Ideological and political education on the educated, the selection of means, the infiltration of needs and art, so as to play a proper role. We gradually realize the transformation of inculcation education to interactive education, offline education and offline education, so as to mobilize the enthusiasm of college students and create a classroom atmosphere of interaction and participation. These work make the ideological and political education work more close to the college students, and lead the college students to resist the erosion of pan entertainment.

\subsection{Construct Communication Platform}

The new media has become an indispensable tool for communication, communication and entertainment for college students, or even a way of life. Ideological and political educators in Colleges and universities should adapt themselves to the development and change of information technology, make use of new media to achieve life education, and establish an equal and interactive communication education with college students. Educators should make good use of new media, through interaction with the students whenever and wherever possible the micro platform, to grasp the idea of dynamic new students, through the micro platform keen awareness of bad ideas hidden in the college students, timely correct guidance, enhance the pertinence of education. Ideological and political education in Colleges and universities should fully realize the influence of the combination of Pan entertainment and modern network technology, and strive to master the voice of new media, and create an effective network platform for ideological and political education for college students. College students are the main use of modern network, they have great interest in network communication, and even become their common way of life. Therefore, the work of Ideological and political education in the development process should be fully combined with the development characteristics of this new era, firmly grasp the advantages and disadvantages of new network media, in order to avoid do short application of network new media, in the use of traditional education methods for the ideological and political education at the same time, the physical and psychological characteristics and needs more should cater to the university students to take more advanced education ideas, and the idea of education well integrated into the network ideological and political education platform to. By expanding the scope and influence of Ideological and political education through network media, universities can set up special columns for ideological and political education, and enhance interaction between teachers and students.

\section{Conclusions}

Under the background of abused entertainment, colleges and universities must carry out a serious analysis of their phenomena and implement a positive and efficient coping strategy to reduce or eliminate their negative effects. According to the characteristics of college students, universities should enrich their educational contents, innovate teaching models and build communication platforms, so as to form a healthy culture learning environment on campus, so as to achieve the healthy and healthy growth of college students.

\section{References}

[1] Yao Lan. Ideological and Political Education under the Background of the Excessive Entertainment Phenomenon in Cyberspace [J]. Journal of Weinan Normal University, 2017, 32(6): 71-77.

[2] Ye Anfa. Study on the Influence of "Pan-entertainment” on Ideological and Political Education in 
Colleges and Universities and Countermeasures [J]. Journal of Heilongjiang College of Education, 2017, 36(8): 94-96.

[3] Yan Zhibin. Countermeasures to the Trend of Pan-entertainment in Ideological and Political Education on College students [J]. Journal of Liuzhou Vocational \& Technical College, 2010, 10(3): 122-125.

[4] Zhang Wenwen. Analysis of "Pan-entertainment” and Ideological and Political Education [J]. Journal of Open University of Guangdong, 2015, 24(2): 89-92. 